\title{
Evalution of Central Venous Catheter Ports Placed by Medical Oncologists: A Single Center Experience.
}

\section{Tıbbi Onkologlar Tarafından Yerleştirilen Santral Venöz Port Kateterlerin Değerlendirilmesi: Tek Merkez Deneyimi}

\author{
Tarık Salman $^{1}$, Doğuş Türkyılmaz ${ }^{2}$, Tuğba Yavuzşen ${ }^{3}$, Işıl Somalı ${ }^{3}$, Ahmet Alacacioğlu' ${ }^{1}$, Doğan Koca ${ }^{4}$, \\ Tuğba Unek ${ }^{3}$, Tülay Akman ${ }^{5}$, Olçun Ümit Ünal ${ }^{6}$, Utku Oflazoğlư ${ }^{1}$, Uğur Yılmaz ${ }^{7}$ \\ ${ }^{1}$ Katip Çelebi Üniversitesi Tıp Fakültesi Tıbbi Onkoloji Bilim Dalı, İzmir, Türkiye \\ ${ }^{2}$ Dokuz Eylül Üniversitesi Tıp Fakültesi Hematoloji Bilim Dalı, İzmir, Türkiye \\ ${ }^{3}$ Dokuz Eylül Üniversitesi Tıp Fakültesi Tıbbi Onkoloji Bilim Dalı, İzmir, Türkiye \\ ${ }^{4}$ Van İstanbul Hastanesi Tıbbi Onkoloji Kliniği, Van, Türkiye \\ ${ }^{5}$ İzmir Tepecik Eğitim ve Araştırma Hastanesi Tıbbi Onkoloji, İzmir, Türkiye \\ ${ }^{6}$ İzmir Bozyaka Eğitim ve Araştırma Hastanesi Tıbbi Onkoloji, İzmir, Türkiye \\ ${ }^{7}$ İzmir Üniversitesi Tıp Fakültesi Tıbbi Onkoloji Bilim Dalı, İzmir, Türkiye
}

\section{ÖZET}

Amaç: Santral Venöz port kateter (SVPK) kanser hastalarının kemoterapi ve palyatif bakımında önemli yer almaktadır. SVPK cerrahi klinikler tarafından yerleştirilmekte ve onkoloji ile cerrahi klinikleri arasında işlem için geçen süre genelde tedavide gecikmeye neden olmaktadır. Biz çalışmamızda literatürde ilk kez bir tıbbi onkoloji kliniği tarafindan yerleştirilen SVPK'lere bağlı komplikasyonlarının incelenmesini amaçladık.

Gereç ve Yöntemler: Dokuz Eylül Üniversitesi Tıbbi Onkoloji Bilim Dalı'nda tıbbi onkoloji hekimleri tarafindan SVPK takılan 2179 kanser hastası çalışmaya alındı. Hastaların tıbbi kayıtları retrospektif olarak incelendi.

Bulgular: 2179 hastaya perkütan yöntemle SVPK takılma işlemi uygulandı. $2055(\% 94,3)$ hastada juguler vene, $90(\% 4,1)$ hastaya femoral ve $34(\% 1,6)$ hastaya subklavyen vene SVPK takıldı. Hastalarımızın $2167(\% 99,4)$ hastada akut komplikasyon görülmezken 12 hastada akut komplikasyon gerçeklești. $9(\% 0.04)$ hastada pnomotoraks, $2(\% 0,009)$ hastada hematom ve $1(\% 0,0046)$ hastada girişime bağlı akut atriyal fibrilasyon atağı komplikasyonları saptandı. Kronik komplikasyonlara bakıldığında $19(\% 0,87)$ lokal port enfeksiyonu, $19(\% 0,87)$ hastada port tıkanması, $15(\% 0,68)$ hastada derin ven trombozu, $11(\% 0,50)$ hastada port çıkması veya kopması, $10(\% 0,45)$ hastada kateterle ilişkili kan damarı enfeksiyonu, $2(\% 0,09)$ hastada cilt nekrozu, $1(\% 0,045)$ hastada port sıkışması (pinch-off sendromu) ve $1(\% 0,045)$ hastada rezervuar giriş yarası olduğu saptandı.

Sonuç: Literatürdeki medikal onkologların yerleştirdiği en fazla hasta sayısına sahip olan çalışmamıza ait veriler incelendiğinde komplikasyon oranının literatürdeki cerrahi kliniklere ait sonuçlardan kötü olmadığını hatta sonuçların pek çok çalışmadan daha iyi olduğunu saptadık. Çalışmamız SVPK yerleştirilmesi yönünde medikal onkologları cesaretlendirici sonuçlara ulaşmıştır.

Anahtar Kelimeler: Santral venöz port kateter, kanser hastaları, tıbbi onkoloji

\section{ABSTRACT}

Objective: The central venous catheter port (CVCP) is a key component of the chemotherapy and palliative care for patients with cancer. The CVCP is placed by surgical clinics, and the period of time it takes to complete the procedure between oncology and surgery clinics usually causes delays in the treatment. The present study aims to investigate the results associated with CVCPs placed by a medical oncology clinic for the first time in the literature.

Material and Method We included 2,179 patients with cancer who underwent a CVCP placement performed by medical oncology physicians within Dokuz Eylül University Medical Oncology Department. The patients' medical records were examined retrospectively.

Results: 2,179 patients underwent a percutaneous CVCP placement procedure. 2,055 (94.3\%) patients had CVCP in their jugular vein, $9(4.1 \%)$ in the femoral vein, and $34(1.6 \%)$ in the subclavian vein. $12(0.6 \%)$ patients exhibited acute complications while 2,167 patients $(99.4 \%)$ had none. We detected pneumothorax in 9 patients $(0.04 \%)$, hematoma in 2 patients $(0.009 \%)$, and 1 patient $(0.0046 \%)$ presented with complications of acute atrial fibrillation associated with the procedure. Chronic complications included $19(0.87 \%)$ local port infections, $19(0.87 \%)$ blocked ports, $15(0.68 \%)$ deep vein thrombosis, $11(0.50 \%)$ displaced ports, $10(0.45 \%)$ catheter-associated blood vessel infections, $2(0.09 \%)$ skin necrosis, 1 $(0.045 \%)$ compressed port (pinch-off syndrome), and $1(0.045 \%)$ wound in the reservoir access.

Conclusion: For the first time in the relevant literature, we found that the complication rates for the CVCPs placed by medical oncologists in a medical oncology clinic were no worse than those reported for the surgery clinics. Our findings encourage medical oncologists to place CVCPs themselves.

Keywords: Central venous catheter, cancer patients, medical oncology 


\section{Giriş}

Onkoloji hastalarının tedavilerinde, damardan erişim araçları, laboratuvar incelemeleri için kan örneklemesi yapılmasında, ameliyat veya kemoterapide ve palyatif tedavilerin verilmesinde kullanılmaktadır. Venöz erişim araçları santral (kateterin ucu vena cava süperiorun üzerinde, atriyumda ya da vena cava inferiorun üst kisminda olan) veya periferik damar yolu erişim araçları (diğer bütün örnekler) olarak da sinıflandırılabilir. Uzun süreli venöz erişim araçları tünelli santral kateterler ve intravenöz portlan içermektedir. Tünelli kateterler genellikle silikon ya da lastikten üretilmektedir ve kapaklı ve kapaksız tipleri mevcuttur. İntravenöz portlar, genellikle titanyum ve/ veya plastik polimerden oluşan bir rezervuar ve buna bağlı silikondan yapılmış kateterden oluşmaktadır. Venöz erişim araçlarının seçiminde hasta ve hastalık özellikleri, kullanım amaçları ve süresi, tedavilerin uygulanış şekli(sürekli infüzyon, günlük intermittan uygulama ), cihazın özellikleri, takılması ve çıkarılmasının hangi şartlarda yapılacağı(hasta başı, ameliyathane), cihazın bakım özellikleri, maliyeti ve komplikasyon oranları gibi faktörler hesaplanır.

Onkoloji hastalarında uzun süreli ve aralıklı kemoterapiler için en uygun araç olması, hastanın daha kolay yıkanması, deri altında gizlenmiş olması dolayısıyla psikolojik bozulma yaratmamas1, tromboz ve enfeksiyon oranının daha düşük olması, dışarıdan bir pansuman bir müdahale gerektirmemesi, hastanın (kişisel hijyen, yüzme ve cinsel yaşam gibi) faaliyetlerini kesintiye uğratmamas1, sadece ayda bir bakım gerektirmesi gibi nedenlerle santral venöz port kateterler (SVPK) kalıcı santral kateterlere tercih edilmektedir.

İntravenöz portlar, 1980 lerden bu yana üretilen ve port gövdesi, septum, tek veya çift lümenli rezervuar ve kateterden oluş-

maktadır. Portlar, 19-22 gauge iğne ile 1000 ila 2000 arasında ponksiyona izin verecek şekilde tasarlanmışlardır. Port tipleri, Mediport ${ }^{\mathrm{TM}}$, Infuse-a-Port $^{\mathrm{TM}}$ and Port-a-Cath ${ }^{\mathrm{TM}}$ lar1 içermektedir. Sistem, özelleşmiş eşiksiz (noncoring)bir iğne (Huber iğnesi) kullanarak perkutan ponksiyonla bolus enjeksiyonlara, infüzyonlara ve kan ürünlerinin verilmesine izin verir. Huber iğnesi, ucunda daha büyük bir alana sahiptir ve düz veya açılı olabilir, iğnenin profili septumun ayrılmasına izin verir. Port gerekli olmadığında iğne çıkarılır. Port iğneleri 72 saate kadar süreli kullanılabilir fakat kan ürünü veya lipit solüsyonları verildiyse 24 saatte değiştirilmelidir. Bu tip iğneler 'rebound' iğne giriş hasarını önlemek için tavsiye edilir $(1,2)$

\section{Santral venöz port takılma tekniği}

Santral venöz port kateter takarken sirasıly sterilizasyon, lokal anestezi, santral ven ponksiyonu ve kılavuz telin yerleştirilmesi, rezervuar cebinin hazırlanması, rezervuarsantral kateter bağlantısını sağlayacak tünelin oluşturulmas1, rezervuarın cebe yerleştirilmesi, kateterin damar içine yerleştirilmesi ve kapatma işlemleri uygulanır. Ardından port kontrol edilir ve pansumanı yapılır. İntravenöz portlarda sıklıkla sağ iç juguler ven kullanılmakla beraber sağ subklavyen ven, sol subklavyen, femoral ven, aksiller vene ve direk sağ atriuma da takılabilir. Öncelikle cerrahi el yıkama ve sterilizasyon şartları sağlanır. Kardiyak monitorizasyon yararlı olabilir. Gerekli malzeme önceden hazırlanır. Așırı tüylü yüzeyler, işlemden kısa süre önce tıraș edilir. Uygun antiseptikle alan temizliği yapılır. Dezenfekte edilen alan ve etrafinda örtülerle oluşturulan steril alan, kılavuz telinin ve henüz kısaltılmamış kateterin ya da işlem yapanları ellerinin değebileceği alanlar da dikkate alınarak geniş tutulmalıdır. Juguler çentik ve sağındaki üçgen palpe edilir. Damar girişi için ponksiyon, juguler çentiğin sağında sternokleidomastoid kasın iki kolunun klavikula ile oluşturduğu üçgenin içinden, lateral kenarın klavikula ile yaptığı köşeden yapılacaktır. İk olarak ponksiyon yapılacak alana lokal anestezi uygulanır, daha sonra kesi ve dilatatör ile dilatasyon yapılacağından yeterli ölçüde anestezi sağlanmalıdır. Sağ internal juguler yaklaşımda juguler çentik palpe edilir. Sağ sternokleidomastoid kasın iki kolu ve klavikulanın yaptığı üçgende klavikula üzerinde lateral köşeden klavikula altına kadar dik girilir. Negatif basınçla sağ meme yönünde horizontal düzlemde 30-45derece açıda ilerlenir. Vene girildiğinde ilerleme durdurularak iğne ucunun ven içinde olduğu doğrulanır. Şırınga iğneden ayrılarak arter 
içinde olmadığı doğrulanır. Kılavuz teli ponksiyon iğnesi içinden gönderilir. Ardından rezervuarın yerleştirileceği alan olan cebin lokal anestezisi yapılır. Lokal anestezinin ardından rezervuarın geçeceği büyüklükte cilt insizyonu yapılır. Eğri pens ve parmak yardımıyla rezervuar için cep açılır. Cep oluşturulduktan sonra rezervuar ile prova yapılır. Cep tabanının iki köşesine daha sonra rezervuarı fikse etmek için kullanmak üzere birer sütür ipi yerleştirilir. Daha sonra tünelin açılmasına geçilir. Kılavuz telinin olduğu bölge derisine $1 \mathrm{~cm}$ 'den küçük bir insizyonla delik açılır. $\mathrm{Bu}$ delikten tünel açmak için kullanılan çubuk ve daha sonra dilatatör geçecektir. Silikon kateter, metal çubuğa iliştirilir. Metal çubuk cep insizyonundan girilerek cilt altında ilerletilir kılavuz teli girişindeki insizyon deliğinden çıkarılır. Çubuk çekilerek kateterin tünel içine yerleşimi sağlanır. Kateter ucu kesilerek serbestleştirilir. Louis açısından itibaren $6-8 \mathrm{~cm}$ ve cep içine uzanacak 2-3 cm' lik pay birakılarak kateterin fazla kısmı kesilerek atılır. Bağlantı bileziği, kateterin distal ucuna geçirilir. Rezervuar, katetere, bağlantı bileziğinin yardımı ile fikse edilir. Cep tabanına bağlı ipliklerin birer ucu, rezervuarın yanındaki saptama deliklerinden geçirilir. Rezervuar, cebe yerleştirilir. Hafif traksiyonla rezervuar çekilerek kateter hafifçe gerilir. Kılavuz teli üzerinden üzerinde kılıf bulunan dilatatör damar içine gönderilir. Dilatatör kılavuz tel üzerinden gönderilmeden, kılavuz tel dilatatörün diğer uçunda tutulabilecek şekilde bir miktar geri çekilmelidir. Dilatatör ilerletildikten sonra k1lavuz teli çekilir. Kılıf içinden dilatatör çekilerek dışarı alınır. $\mathrm{Bu}$ işlem sırasında kılıf parmakla sıkıştırılarak hava ya da kan kaçağı engellenir. Kılıf içinden kateter damar içine ilerletilir. Kateter ilerletildikten sonra kılıfin iki kulağı birbirinde ayrılarak kılıf kateter içeride kalacak şekilde ikiye yırtılır. $\mathrm{Bu}$ yırtma sirasında bir yardımc1, kateterin yerinde kalması için kateter üzerine parmağıyla bastırır. Port cep içine itilerek fiksasyon için takılan ipliklerin dügümleri atılır ve fazlalıkları kesilir. Cep insizyonu sıkı bir dikişle kapatılır (matriks tipi) Damar giriş insizyonu basit dikişle kapatılır. Rezervuar palpe edilir. Port iğnesi ile girilir, aspirasyon yap $111 \mathrm{r} .10 \mathrm{ml}$ fizyolojik serum ile kateter yıkanır. $100 \mathrm{IU} / \mathrm{ml}$ heparin içeren $5 \mathrm{ml}$ fizyolojik serum ile kateter flaşlanır. Flaşlamanın bitimine doğru pozitif basınç uygulanır iken iğne şırınga ile birlikte geri çekilir (Şekil 1).

Portun merkezi, kolayca palpe edilebilen ve hasta mahremiyetinin korunduğu yer olan gögüs duvarına, sıklıkla deltopektoral oluğun inferior ve medialine yerleştirilir. Portun kırılmasının ve yer değiştirmesinin önüne geçmek için portun altta bulunan pektoralis fasyasına fiksasyonu önemlidir. Subkutan port cebinin yaratılmas1, seroma oluşumunu ve dolayısıyla port alanı enfeksiyonu riskini azaltmak için minimum diseksiyonla yapılmalıdır.

\section{Santral venöz port kateter takılmasının kontrendikasyonları}

Port takılması için kontrendikasyonlar koagulasyon bozuklukları, trombosit fonksiyon bozukluklar1 ya da trombositopeni, vena cava süperior dallarındaki tromboz varlığı, cilt sorunlarıdır.

\section{Santral venöz port kateter komplikasyonları}

Port komplikasyonları, akut ve kronik komplikasyonlar olarak siniflandırılabilir. Perop ve akut komplikasyonlar arteryel ponksiyon, hematom, hava embolisi, pnömotoraks ve damar perforasyonu iken kronik komplikasyonlar kateterle ilişkili tromboz, enfeksiyonlar, Pinch off sendromu, kateter kopması, yırtılması ve yer değiştirmesi, retraksiyonu, port çember defekti, ilaç ekstravazasyonudur (3-6) 


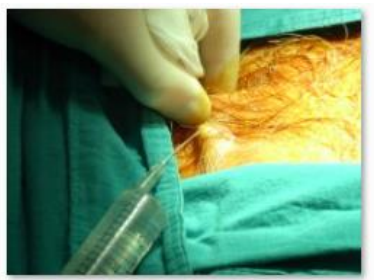

1- LOKAL ANESTEZI

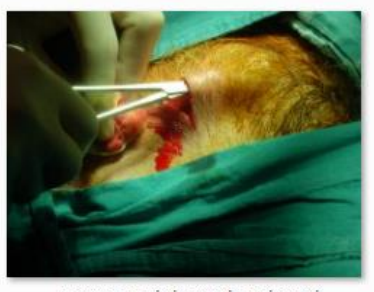

5- PORT CEBININ GENIŞLETILMESI

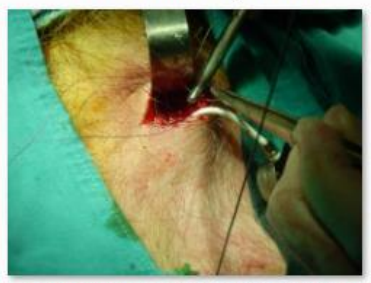

9- PORT REZERVUARI- KATETER BIRLESTTIRILMES

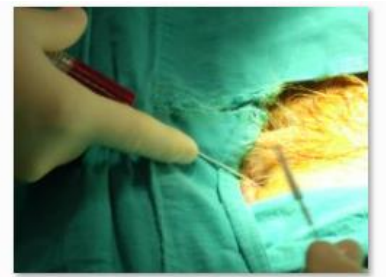

2- SANTRAL KATETER PONKSIVONU

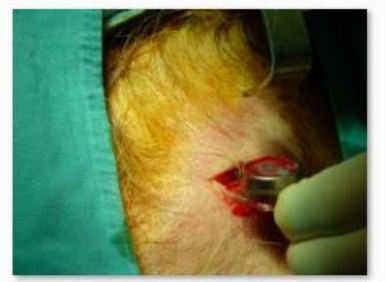

6- PORT CIHAZININ DENENMESI

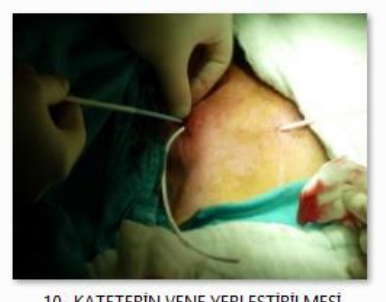

10- KATETERIN VENE YERLEȘTiRILMESI

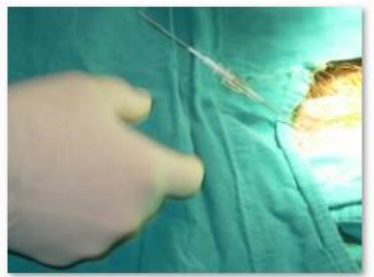

3- KILAVUZ TELININ YERLEȘTiRiLMESI

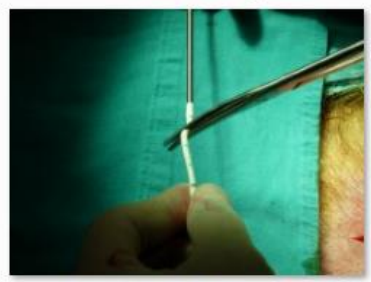

7- KATETERIN CILTALTI IÇIN HAZIRLANMASI

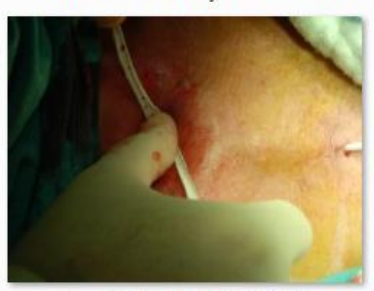

11- DILATATÖRÜN ÇEKILMESI

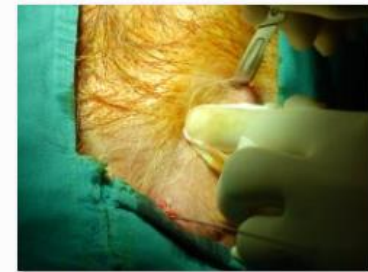

4- PORT CEBIBIN AÇILMASI

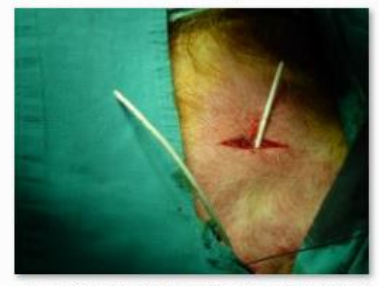

8- KATETERIN CILTALTINA YERLEȘTIRILMESI

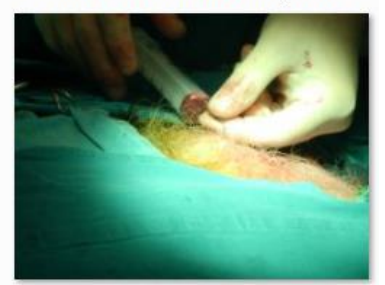

12- PORT CIHAZININ DENENMESI

Şekil 1: Santral venöz port kateter takılmasının aşamaları

\section{Materyal ve Metod}

Dokuz Eylül Üniversitesi Tıbbi Onkoloji Bilim Dalı'nda tıbbi onkoloji hekimleri tarafindan SVPK takılan 2179 kanser hastası çalışmaya alındı. Hastaların tıbbi kayıtları retrospektif olarak incelendi.

Yaş, cinsiyet, primer hastalık tanısı, bir hastaya uygulanan toplam port kateter sayıs1, port kateterin uygulandığ 1 venler, port takılma ve çıkartılma tarihleri, komplikasyon türleri (tromboz, enfeksiyon ve mekanik olmak üzere), enfeksiyona ait alt komplikasyon grupları (akut ve kronik komplikasyonlar olmak üzere), akut komplikasyonlar (arteryel ponksiyon, hematom, hava embolisi, pnömotoraks ve damar perforasyonu olmak üzere), kronik komplikasyonlar (kateterle ilişkili tromboz, enfeksiyonlar, mekanik komplikasyonlar olmak üzere), (cep, lokal port enfeksiyonu, kateter ilişkili kan dolasım enfeksiyonu olmak üzere), mekanik alt komplikasyon grupları (tıkanma-tromboz, yer değiştirme, çıkma-kopma, port üzeri cilt defekti (yara-nekroz), parsiyel tıkanıklık, ekstravazasyon, lokal şişlik ve kanama olmak üzere) kaydedildi ve tüm bu veriler Excel programına aktarıldı.
Yukarda listesi verilen hasta verileri SPSS programı aracılığıyla analiz edildi. Hastalarla ilgili tanımlayıcı istatistikler elde edildi. Yaş gruplarına göre hastaların dağılımı, port takılma tarih araliklarına göre port sayılarının dağılımı, tanılara göre hastaların dağılımı, takılan bölgeye göre hastaların dağılımı, akut ve kronik komplikasyonların sayı, yüzde ve yıllara göre dağılımları, port çıkarılma nedenlerinin komplikasyonlara göre dağılımları hesaplandı.

\section{Bulgular}

Dokuz Eylül Üniversitesi Tibbi Onkoloji bölümünce takip edilen SVPK gereksinimi olan 2179 hastaya tıbbi onkologlar tarafindan SVPK takılma işlemi yapıldı. Hastaların 1182 (\%54,2)'ü erkek, $997(45,8)$ 'i kadındı. Yaş dağılımı 17-89 arasında değişmekteydi ve ortalama yaş 58 olarak saptand1. Yaş grupları tablo 1'de ve tanılara göre dağ 1 lım tablo 2'de gösterilmektedir.

2179 hastaya SVPK işlemi uyguland. Bunlardan 2017 hastaya bir kez port tak1lırken 145 'ine $2 \mathrm{kez}, 14$ 'üne $3 \mathrm{kez}$ ve 3 hastaya $4 \mathrm{kez}$ port takıldı. 145 hastaya $1 \mathrm{kez}, 14$ hastaya 2 kez ve 3 hastaya 4 kez olmak üzere toplam 286 
port çıkarma işlemi uygulandı. SVPK 'lerin tamamı perkutan yöntemle takıldı. Takılma yerlerine göre dağılımda ise $2055(\% 94,3)$ ' $i$ juguler, $90(\% 4,1)$ femoral ve $34(\% 1,6)$ 'i subklavyen vene takild.

Tablo 1: Santral venöz port kateter takılan hastaların yaş gruplarına göre dağılımı

\begin{tabular}{|ccc|}
\hline Yaş grubu & Kişi sayısı & Yüzde \\
\hline $17-24$ & 34 & 1,6 \\
\hline $25-64$ & 1505 & 69,0 \\
\hline 65 ve üzeri & 640 & 29,4 \\
\hline toplam & 2179 & 100 \\
\hline
\end{tabular}

Tablo 2: Santral venöz port kateter takılan hastaların tanıları

\begin{tabular}{|c|c|c|}
\hline Hastalık & $\begin{array}{c}\text { Görüllme } \\
\text { Sıklığı }\end{array}$ & Yüzde \\
\hline akciğer kanseri & 92 & 4,2 \\
\hline $\begin{array}{l}\text { baş boyun } \\
\text { kanserleri }\end{array}$ & 82 & 3,8 \\
\hline $\begin{array}{c}\text { böbrek-mesane } \\
\text { kanseri }\end{array}$ & 13 & 0,6 \\
\hline $\begin{array}{c}\text { hematolojik } \\
\text { kanser }\end{array}$ & 51 & 2,3 \\
\hline karaciğer kanseri & 57 & 2,6 \\
\hline kolon kanseri & 608 & 27,9 \\
\hline meme kanseri & 276 & 12,7 \\
\hline mide kanseri & 308 & 14,1 \\
\hline over kanseri & 50 & 2,3 \\
\hline özefagus kanseri & 34 & 1,6 \\
\hline pankreas kanseri & 184 & 8,4 \\
\hline rektum kanseri & 270 & 12,4 \\
\hline $\begin{array}{c}\text { safra kesesi } \\
\text { kanseri }\end{array}$ & 54 & 2,5 \\
\hline $\begin{array}{l}\text { serviks-uterus } \\
\text { kanseri }\end{array}$ & 16 & 0,7 \\
\hline $\begin{array}{c}\text { testis-prostat } \\
\text { kanseri }\end{array}$ & 14 & 0,6 \\
\hline diğer & 39 & 1,8 \\
\hline toplam & 2179 & 100,0 \\
\hline $\begin{array}{l}\text { Toplam } \\
(\% 99,4) \text { 'sinda } \\
\text { görülmezken } 12\end{array}$ & $\begin{array}{rr}2179 & \mathrm{~S} \\
\text { akut } & \\
\text { astada } & \text { akl }\end{array}$ & $\begin{array}{l}\text { SVPK'in } 2167 \\
\text { komplikasyon } \\
\text { kut komplikasyon }\end{array}$ \\
\hline
\end{tabular}

gerçekleşti: 9 (\%0.04) hastada pnomotoraks; 2 $(\% 0,009)$ hastada hematom ve 1 $(\% 0,0046)$ 'inde girişime bağlı akut atriyal fibrilasyon atağı komplikasyonları oldu. Akut komplikasyonlar ve yıllara göre dağılımı tablo 3'de gösterilmektedir.

Kronik komplikasyonlara bakıldığında $19(\% 0,87)$ hastada lokal port enfeksiyonu; 19 $(\% 0,87)$ hastada port tıkanması, $15(\% 0,68)$ hastada derin ven trombozu, $11(\% 0,50)$ hastada port çıkması veya kopması, $10(\% 0,45)$ hastada kateterle ilişkili kan damarı enfeksiyonu, $2(\% 0,09)$ hastada cilt nekrozu, $1(\% 0,045)$ hastada port sıkışması (pinch-off sendromu $), 1(\% 0,045)$ hastada rezervuar giriş yaras1 olduğu saptand1. Kronik komplikasyonlar ve yıllara göre dağılımları Tablo 4'da gösterilmektedir.

Santral venöz port kateter çıkarılan hastalara baktığımızda 286 port çıkarma işleminin $213(\% 74,4)$ hastada tedavi bitimi, $19(\% 6,6)$ hastada port t1kanmas1, $15(\% 5,2)$ hastada derin ven trombozu, $14(\% 4,8)$ hastada lokal port enfeksiyonu, $11(\% 3,8)$ hastada port çıkması veya kopması, $10(\% 3,4)$ hastada kateterle ilişkili kan damarı enfeksiyonu, $2(\% 0,6)$ hastada cilt nekrozu, 1 $(\% 0,3)$ hastada port sıkışması (pinch-off sendromu) ve $1(\% 0,3)$ hastada rezervuar giriş yaras1 nedeniyle yapıldığı görüldü. SVPK çıkarılma nedenleri Tablo 5'de gösterilmektedir.

\section{Tartışma}

Uzun süreli venöz erişim araçları olan SVPK kullanımı 1982'de başlanmış olup o günden bu yana kullanımları ve komplikasyonları rapor edilmeye devam etmektedir. Kemoterapi, kan ürünleri, total parenteral besleme, antibiyotikler ve diğer intravenöz tedavilerin ve kan örneklemelerinin yapılması konusunda oldukça yaygınlaşmış ve çoğu merkezde uygulamanın önemli bir parçası haline gelmiştir.

İntravenöz port cihazları ilk kez 1982 de MD Anderson Kanser Merkezinde, John Niederhuber tarafindan açık cerrahi (cut-down) yöntemiyle sefalik ven kullanılarak takılmıştır. (7) Daha sonra, cerrahi uzmanlık gerektirmemesi, daha kolay ve güvenli yol olması nedeniyle perkutan yöntem daha s1k kullanılmaya başlanmıştır. Bu yöntemde daha sik olarak juguler ven ve subklavyen ven Adress for correspondence: Uzm. Dr. Tarık Salman, Atatürk Eğitim Ve Araştırma Hastanesi Tıbbi Onkoloji Kliniği Hasan Tahsin Cd Karabağlar 35100 İzmir - Türkiye e-mail: drtariksalman@gmail.com

Available at www.actaoncologicaturcica.com Copyright $\odot$ Ankara Onkoloji Hastanesi 
Tablo 3: Akut komplikasyonlar ve yıllara göre dağılımı

\begin{tabular}{|lllllllllll|}
$\begin{array}{l}\text { yllar/ } \\
\text { komplikasyon }\end{array}$ & $\mathbf{2 0 0 4}$ & $\mathbf{2 0 0 5}$ & $\mathbf{2 0 0 6}$ & $\mathbf{2 0 0 7}$ & $\mathbf{2 0 0 8}$ & $\mathbf{2 0 0 9}$ & $\mathbf{2 0 1 0}$ & toplam & yüzde \\
\hline pnomotoraks & - & 1 & 2 & 1 & 3 & 2 & - & 9 & $(\% 0.04)$ \\
\hline kanama & 1 & - & - & 1 & - & - & - & 2 & $(\% 0.009)$ \\
\hline $\begin{array}{l}\text { atriyal } \\
\text { fibrilasyon }\end{array}$ & - & - & 1 & - & - & - & - & 1 & $(\% 0.004)$ \\
\hline toplam & 2 & 1 & 3 & 2 & 3 & 2 & - & 12 & $(\% 0.06)$ \\
\hline
\end{tabular}

Tablo 4: Kronik komplikasyonlar ve yıllara göre dağılımı

\begin{tabular}{|c|c|c|c|c|c|c|c|c|c|}
\hline $\begin{array}{l}\text { yillar/ } \\
\text { komplikasyon }\end{array}$ & 2004 & 2005 & 2006 & 2007 & 2008 & 2009 & 2010 & toplam & yüzde \\
\hline port t1kanması & 2 & 4 & 5 & 1 & 4 & 2 & 1 & 19 & 0,87 \\
\hline DVT & 2 & 1 & 6 & 3 & 2 & 1 & & 15 & 0,68 \\
\hline lokal port enfeksiyonu & 3 & 3 & 2 & 3 & 4 & 3 & 1 & 19 & 0,87 \\
\hline kikde & & 1 & 3 & 3 & 1 & 1 & 1 & 10 & 0,45 \\
\hline port ç1kmas1- kopmas1 & & 1 & 3 & 2 & 2 & 3 & & 11 & 0,5 \\
\hline port s1kışmas1 & & & 1 & & & & & 1 & 0,04 \\
\hline cilt nekrozu & & & 1 & 1 & & & & 2 & 0,09 \\
\hline rezervuar giriş yarası & & 1 & & & & & & 1 & 0,04 \\
\hline toplam & 7 & 11 & 21 & 13 & 13 & 10 & 3 & 78 & 3,55 \\
\hline
\end{tabular}

Kısaltmalar:DVT (derin ven trombozu), kikde (kateterle ilişkili kan damarı enfeksiyonu)

Tablo 5: Santral venöz port kateter çıkarılma nedenleri

\begin{tabular}{|lcc|}
\hline $\begin{array}{l}\text { SVPK çıarılma } \\
\text { nedenleri }\end{array}$ & sayı & yüzde \\
\hline tedavi bitimi & 213 & $\% 59,2$ \\
\hline $\begin{array}{l}\text { lokal port } \\
\text { enfeksiyonu }\end{array}$ & 14 & $\% 12,9$ \\
\hline port tıkanması & 19 & $\% 11,7$ \\
\hline $\begin{array}{l}\text { derin ven } \\
\text { trombozu }\end{array}$ & 15 & $\% 7,4$ \\
\hline $\begin{array}{l}\text { port ç1kmas1- } \\
\text { kopması }\end{array}$ & 11 & $\% 4,9$ \\
\hline kikde & 10 & $\% 1,2$ \\
\hline cilt nekrozu & 2 & $\% 1,2$ \\
\hline port s1k1şması & 1 & $\% 0,6$ \\
\hline $\begin{array}{l}\text { rezervuar giriş } \\
\text { yarası }\end{array}$ & 1 & $\% 0,6$ \\
\hline toplam & 286 & 100 \\
\hline
\end{tabular}

kullanılmıştır. Böylece açık cerrahi yöntemle \%70-94 civarında olan başarı oranı perkutan yöntemle \%100' e dayanmıştır. (8-10). Radyoloji kılavuzluğunda intravenöz port ci- haz1 tak1lmas1 ise 1992'den bu yana uygulanmaktadır.

Girişim süresinin daha kısa olması ve pnömotoraks riskinin daha az olması nedeniyle juguler ven subklavyen vene göre daha fazla tercih edilmektedir. (11). Biz, hastalarımıza daha çok juguler ven aracılığıyla perkutan yöntemi kullanarak intravenöz port yerleştirme işlemini gerçekleştirdik. Yirmiyedi yıldır açık cerrahi ve perkutan yöntemle intravenöz port takılan hastaları değerlendiren Isidoro Di Carlo ve ark. yaptığı derlemede, açık cerrahi yöntemde daha çok sefalik venin tercih edildiği görülürken, perkutan yöntemde subklavyen venin daha sık tercih edildiği saptanmıştır. Akut komplikasyon oran1 perkutan yolla yapılanlarda cerrahi yolla yapılanlara göre daha yüksek bulunmuştur (sırasılyla \%4,5 e karşıllk \%0,9) (8). Bizim vaka serimizde akut komplikasyonların oranı \%0,55 olarak daha düşük saptanmıştır. Bunun nedeni Isidoro Di Carlo ve ark. yaptığ derlemede perkutan yöntem olarak daha sık subklavyen ven tercih edilirken bizim vakalarımızda juguler venin 
tercih edilmesi nedeniyle olabilir.Biffi ve ark. Vemöz port kateter yerleştirilmesi için en uygun yerin vena kava yoluyla sağ atriyuma yerleştirilmesi olduğunu belirtmişlerdir (12)

Akut komplikasyonlardan, ciddi klinik, ekonomik ve psikolojik sonuçlara neden olmasindan dolayı en korkulan komplikasyon pnömotorakstır. Literatürde pnömotoraks görülme oranı \%0,5-6 arasındadır. (13). Bizim vaka grubumuzda pnömotoraks oranı $\% 0.41$ olarak literatüre göre daha az idi.

Hematom görülmesi yanlış teknikten ya da hemostaz bozukluğundan kaynaklanmaktadır. Bu komplikasyona katkıda bulunan risk faktörleri ise obezite, ilgili alana önceden yapılan girişimler ve radyoterapi, çoklu enjeksiyonlar ve operatörün deneyimsizliğidir. Literatürde hematom görülme sıklığı \%1,8-8 arasında değişmektedir. (11) Hematom sıklığ Isidoro Di Carlo ve ark. yaptığ 1 derlemede perkutan teknik için $\% 0,06$ iken açık cerrahi teknikte \%0,04 olarak bulunmuştur (8). Bizim toplam 2179 vakamızın sadece 2 tanesinde hematom görülmüştür ve sıklığı $\% 0,09$ olarak saptanmıştır.

Girişime bağlı akut atriyal fibrilasyon (AF) kateter ucunun sağ atriyuma geçmesi nedeniyle olur. Literatürde girişime bağlı akut AF oranı \%0,1-0,9 arasında bulunmuştur. Isidoro Di Carlo ve ark. yaptığ 1 derlemede AF cut-down grubunda $\% 0,02$ iken perkutan grupta \%0,03 olarak gözlenmiş. (14). Vakalarımızın sadece 1 tanesinde AF görülmüştür ve sıklığ1 $\% 0,0046$ olarak saptanmıştır.

Diğer akut komplikasyonlardan arteryel ponksiyon, hava embolisi ve damar perforasyonu hiçbir vakamızda görülmemiştir.

Literatüre göre SVPK ilişkili enfeksiyon riski \%0,6-27'dir (15). Enfeksiyon riski, kateter tipi, lokalizasyonu ve hastanın durumuna bağlıdır. SVPK'i olan immünsüprese hastalarda enfeksiyon riski ortanca 0,2 enfeksiyon/1000 kateter günü olarak saptanmıştır (16). 2003'de Alman Hematoloji ve Onkoloji Derneği enfeksiyon hastalıkları kılavuzunda enfeksiyon_tanımları düzenlenmiştir. Buna göre kateter kolonizasyonu, bakteriemi veya enflamasyonun klinik bulguları olmaksızın kateter yüzeyinde bakteri olmasıdır. Gerçek kateter enfeksiyonları ise sistemik enfeksiyon bulguları olmaksızın kateter alanında enfeksiyonla seyreden lokal port enfeksiyonlar, aynı mikroorganizmanın hem kateter alanından alınan kan kültüründe hem de periferik kan kültüründe ürediği bakteriemi/fungemi ve enfeksiyonun yerleştirilen port sisteminin cilt altı kısmına yayıldığı cep enfeksiyonlarını içerir (17). Zerati ve ark. SVPK için en öenmli enfeksiyon riskini hospitalizasyon ve femoral girişim olarak belirtmişlerdir (18).

Onkoloji hastaları venöz tromboz için artmış riske sahiptirler. Kateter yerleştirilmesi bu riski daha da arttırır. Kateterle ilişkili tromboz, kateterin yerleştiği alanda tromboz olmasını ve kateter lümeninin tıkanmasını içerir. Venöz tromboz asemptomatiktir ya da ipsilateral kol, boyun veya bacakta ağrı ve şişlikle kendisini gösterir. Trombotik kateter oklüzyonu kısmi veya tam olabilir, enfeksiyona neden olabilir (19). Onkoloji hastalarında kateterle ilişkili tromboz riski çeşitli çalışmalara göre \%12-64 arasında değişmektedir. (19-22) Solid tümörlü ve hematolojik maligniteli hastalarla yapılmış 4 prospektif kateterle ilişkili tromboz çalışmasında tromboz oranı \%37,5- 66 arasında bulunmuștur. (23-26). Bizim vakalarımız arasında $19(\% 0,85)$ hastada port tıkanmas1, $12(\% 0,55)$ hastada derin ven trombozu olmak üzere toplam $31(\% 1,4)$ hastada kateterle ilişkili tromboz görülmüştür. Kateterle ilişkili tromboz üzerine eklenmiş enfeksiyon hiçbir vakamızda görülmemiştir. Kliniğimizde kateterle ilişkili tromboz oranının düşük görülmesinin sebepleri açısından kateter lokalizasyonu olarak daha çok juguler venin seçiliyor olması ve kateter bakımlarının düzenli sıklıkta yapılıyor olması düşünülebilir. Enfeksiyon eklenmiş vakanın olmamasının sebepleri ise hekim, hemşire, hasta eğitimlerinin iyi olması ve takipte dikkatli olunmasına bağlı olarak trombozların erken fark edilerek tromboz tedavisinin kısa süre içinde başlanması olabilir. Asherani ve ark. kanser hastalarında tromboz riskinde SVPK uygulamasını bağımsız risk faktörü olarak belirtmişlerdir (27). Hemşirelerin eğitimi ve dikkati tromboz riskini özellikle evde bakım hastalarında azaltmaktadır (28)

Literatürde port çıkması, kopması $\%$ 0,1-2 arasında görülmektedir (29-31). Bu durumda port cihazından ilaç gönderilmeye başladığında port çemberi üzerinde yoğun bir ağrı hissedilir. Hasta hareketleri de rol 
oynamasına karşın intravenöz port takılırken çok dikkatli olunması gerektiği oldukça açıtır. Kateter takarken kateter-rezervuar bağlantısının kontrol edilmesi gereklidir. $\mathrm{Bu}$, sistemin güvenliği açısından son derece önemli ve yeterlidir. Vakalarımı arasında port çıkması kopmasının $8 \quad(\% 0,036)$ hastada gerçekleştiği görülmüştür. Az görülmesinin nedenleri arasında kateter lokalizasyonu olarak daha çok juguler venin seçilmesi, port takılırken kullanılan malzemelerin ve port cihazını yerleştiren hekimin kateter rezervuar bağlantısı kontrolünü dikkatle yapıyor olması sayılabilir.

Port sıkışması (pinch-off sendromu), kateterin klavikula ile birinci kosta arasina sıkışması durumuna verilen isimdir. Tipik olarak infraklavikuler yol üzerinden kateterin subklavyen vene perkutan olarak yerleştirilmesinden kaynaklanmaktadır Kateterin sıkışması, akımın geçici süreyle bozulmasina, kateterin tam tıkanmasina ve hatta kopmasina neden olabilmektedir. Klinikte kan almada ya da infüzyonların verilmesinde dirençle karşılaşılır. Literatürde port sıkışması (pinch-off sendromu )sıklığ1 $\% 5$ 'e kadar görülmektedir $(32,33)$. Hastalarımızin sadece 1 tanesinde port s1kışmas1 (pinch-off sendromu) görülmüştür.

SVPK uygulamasinın kanser hastalarında yaygınlaşması ve komplikasyonların geniş hasta serilerinde gösterilmesi sonrası SVPK uygulamalarına yönelik rehberler yayınlanmaya başlanmıştır. ESMO bu konuda bir rehber yayınlamıştır (34). Bu rehberde öne çıkan öneriler olmuştur. SVPK yerleştirilmesinin ultrasonagrafi eşliğinde yapılmasının komplikasyon oranını düşürdüğg̈ belirtilmiştir

Elektrokardiyografi (EKG) kullanımı ile SVPK için ideal olan să̆ atriyuma yerleşimin anlaşılması ile aritmi kontrolünün daha iyi olacağı konusunda görüş bildirilmiştir (36).

Sonuç olarak kanser hastalarının tedavisinin her aşamasında hastalar için önemli avantajlar sağlayan SVPK özellikle kalp-damar cerrahisi ve genel cerrahi klinikleri tarafindan takılmaktadır. Hastanın tıbbi onkoloji kliniği tarafindan yönlendirilmesi ile işlemin tamamlanması arasındaki süre sevk edilen kliniklerin yoğunluğu nedeniyle uzamakta ve tedavide gecikmelere neden olmaktadır. Uygun eğitim ve deneyim sonrasi tıbbi onkoloji klinikleri kendi hastalarına SVPK yerleştirilmesi yönünde, çalışmamızdaki hasta sayısının çokluğu ve komplikasyon oranlarının literatürdeki cerrahi kliniklerine benzer hatta az görülmesi nedeniyle cesaretlendirilebilir. $\mathrm{Bu}$ sayede tedavi gecikmesinin önüne geçilmesi veya palyatif bakımın daha kaliteli verilmesi sağlanabilir. Sosyal güvenlik kurumu ve sağl1k hukukunda bu konuda sorun oluşturabilecek durumlara güncel mevzuata göre girişim öncesinde dikkat edilmelidir.

\section{Çıkar Çatışması: Yok}

\section{Kaynaklar}

1.Schwarz RE, Groeger JS, Coit DG: Subcutaneously implanted central venous access devices in cancer patients: a prospective analysis. Cancer 1997;79: 1635-1640.

2.Vescia S, Baumgartner AK, Jacobs VR et al. Management of venous port systems in oncology: a review of current evidence. Ann Oncol 2008;19:915.

3.Lokich JJ, Bothe A, Jr., Benotti P, Moore C: Complications and management of implanted venous access catheters. J Clin Oncol 1985;3:710-717.

4.Ballarini C, Intra M, Pisani Ceretti $A$ et al.Complications of subcutaneous infusion port in the general oncology population. Oncology 1999;56:97102

5.Kurul S, Saip P, Aydin T: Totally implantable venousaccess ports: local problems and extravasation injury. Lancet Oncol 2002;3:684-692.

6.Yildizeli B, Lacin T, Batirel HF, Yuksel M: Complications and management of long-term central venous access catheters and ports. $\mathrm{J}$ Vasc Access 2004; 5:174-178

7. Niederhuber JE, Ensminger W, Gyves JW et al. Totally implanted venous and arterial access system to replace external catheters in cancer treatment. Surgery. 1982;92:706-12.

8. Di Carlo I, Barbagallo F, Toro A, Sofia M, Lombardo $\mathrm{R}$, Cordio S. External jugular vein cutdown approach, as a useful alternative, supports the choice of the cephalic vein for totally implantable access device placement. Ann Surg Oncol. 2005;12:570-3.

9. Sarzo G, Finco C, Parise P et al. Immediate and longterm complication of prolonged Venous access device (PVAD): a comparison between surgical cutdown and percutaneous techniques. Int $\mathbf{J}$ Angiol. 2004;13:203-9.

10. Chang HM, Hsieh CB, Hsieh HF, Chen TW, Chen CJ, Chan DC, Yet al. An alternative technique for totally implantable central venous access devices. A retrospective study of 1311 cases. Eur J Surg Oncol. 2006;32:90-3.

11. Cil BE, Canyig it $\mathrm{M}$, Peynirciog lu $\mathrm{B}$ et al. Subcutaneous venous port implantation in adult patients: a single center experience. Diagn Interv Radiol. 2006;12:93-8 
12. Biffi R, Pozzi S, Bonomo G et Al. Cost effectiveness of different central venous approaches for port placement and use in adult oncology patients: evidence from a randomized three-arm trial.Ann Surg Oncol. 2014 Nov;21(12):3725-31

13. Grannan KJ, Taylor PH. Early and late complications of totally implantable venous access devices. J Surg Oncol. 1990;44:52.

14. Biffi R, de Braud F, Orsi F et al. Totally implantable central venous access ports for long-term chemotherapy. A prospective study analyzing complications and costs of 333 devices with a minimum follow- up of 180 days. Ann Oncol 1998;9:767-773.

15.Ballarini C, Intra M, Pisani Ceretti A et al. Le complicanze precoci e tardive dei sistemi venosi impiantabili per chemioterapia a lungo termine nei pazienti oncologici. Osp Ital Chir. 1997;6:517-23.

16.D'Angelo FA, Ramacciato G, Aurello $P$ et al. Alternative insertion sites for permanent central venous access devices. Eur J Surg Oncol. 1997;23:547-9.

17. Bothe A Jr, Piccione W, Ambrosino JJ et al. Implantable central venous access system. Am J Surg. 1984;147:565-9.

18. Zerati AE, Figueredo TR, de Moraes RD, da Cruz $\mathrm{AM}$ et al.Risk factors for infectious and noninfectious complications of totally implantable venous catheters in cancer patients $\mathrm{J}$ Vasc Surg Venous Lymphat Disord. 2016 Apr;4(2):200-5

19.Champault G. (1985) Completely implantable catheters for anticancer chemotherapy. A French experience of 325 cases. J Chir (Paris). 122:269-72.

20.Stanislav GV, Fitzgibbons RJ Jr, Bailey RT Jr, Mailliard JA, Johnson PS, Feole JB. Reliability of implantable central Venous access devices in patients with cancer. Arch Surg. 1987;122:1280-3.

21.Starkhammar H, Bengtsson M. Totally implanted device for venous access. Experience in tumour patients. Acta Radiol Oncol. 1985;24:173-6.

22.Morris SL, Jaques PF, Mauro MA. Radiology-assisted placement of implantable subcutaneous infusion ports for long-term Venous access. Radiology. 1992;184:149-51.

23.Koonings PP, Given FT Jr. Long-term experience with a totally implanted catheter system in gynecologic oncologic patients. J Am Coll Surg. 1994;178:164-6.

24. Bruni R, Bartolucci R, Chirco L. I sistemi d'accesso venoso totalmente impiantabili. Chir. 1996;9:146-9.
25. Bertoglio S, Meszsaros P, Disomma C, Moresco L, Cafiero F, Gipponi M, et al. Long-term central venous access in oncology. Review of a caseload of 750 cases. Minerva Chir. 1996;51:427-31.

26. Laurenzi L, Fimiani C, Faglieri N, Natoli S, Milasi G, Tirelli W, et al. Complications with fully implantable venous access systems in oncologic patients. Tumori. 1996;82:232-6.

27. Ashrani AA, Gullerud RE, Petterson TM, Marks RS, Bailey KR, Heit JA Risk factors for incident venous thromboembolism in active cancer patients: A population based case-control study.Thromb Res. 2016 Mar;139:29-37

28. Milani A, Mazzocco K, Gandini S, Pravettoni G et al Incidence and Determinants of Port Occlusions in Cancer Outpatients: A Prospective Cohort Study.Cancer Nurs. 2016 Feb 26

29.Aldrighetti L, Paganelli M, Caterini R, Catena M, Ronzoni M, Ferla G. Safety and efficiency of totally implantable devices for prolonged venous access. A prospective study. J Chemother. 1996;8:393-6.

30.Kock HJ, Pietsch M, Krause U, Wilke H, Eigler FW. Implantable vascular access systems: experience in 1500 patients with totally implanted central venous port systems. World J Surg. 1998;22:12-16.

31. Domingo P, Fontanet A, Sa'nchez F, Allende L, Vazquez G. Morbidity associated with long-term use of totally implantable ports in patients with AIDS. Clin Infect Dis. 1999;29:346-51.

32.Boussen H, Mtaallah M, Dhiab T, Khalfallah S, Jerbi G, Hechiche M, et al. Evaluation of implantable sites in medical oncology in Tunisia. Prospective study of 205 cases. Ann Fr Anesth Reanim. 2001;20:509-13.

33. Milani A, Mazzocco K, Gandini S, Pravettoni G et al Incidence and Determinants of Port Occlusions in Cancer Outpatients: A Prospective Cohort Study.Cancer Nurs. 2016 Feb 26

34. Sousa B, Furlanetto J, Hutka M et $\mathrm{Al}$. Central venous access in oncology: ESMO Clinical Practice Guidelines. Ann Oncol. 2015 Sep;26 Suppl 5:v15268

35. Lamperti M, Bodenham AR, Pittiruti $M$ et Al. International evidence-based recommendations on ultrasound-guided vascular access. Intensive Care Med. 2012 Jul;38(7):1105-17.

36. Pittiruti M, Bertollo D, Briglia E et Al. The intracavitary ECG method for positioning the tip of central venous catheters: results of an Italian multicenter study. J Vasc Access. 2012 JulSep;13(3):357-65. 